\title{
PERBEDAAN PENGARUH LATIHAN PASSING MENGGUNAKAN TARGET DAN LATIHAN PASSING BERPASANGAN TERHADAP KEMAMPUAN PASSING PADA SEKOLAH SEPAK BOLA (SSB) PUTRA MOJOSONGO CLUB TAHUN 2020
}

\author{
Muhammad Khoirul Huda a, Dr. Nuruddin Priya Budi Santoso, M.Or b, Agustanico Dwi \\ Muryadi, S.Pd, M.Pd ${ }^{c}$ \\ abc Physical Education, Universitas Tunas Pembangunan Surakarta, Surakarta, Indonesia. \\ email: ${ }^{a}$ khoirulhuda@gmail.com
}

\begin{tabular}{l}
\hline I N F O A R T I K E L \\
\hline Sejarah artikel: \\
Menerima 1Juli 2021 \\
Revisi 21 Juli 2021 \\
Diterima 31 \\
Online 5 Agustus 2021
\end{tabular}

Kata kunci:

Latihan Menggunakan

Target, Latihan

Berpasangan, Passing

Sepak Bola

\section{Keywords: \\ Exercise Using Target, Pair Training, Passing, Football}

Style APA dalam mensitasi artikel ini: [Heading sitasi] Muhammad Khoirul Huda. (2021). Judul Artikel. Register: Jurnal Ilmiah Perbedaan Pengaruh Latihan Passing Menggunakan Target dan Latihan Passing

Berpasangan Terhadap Kemampuan Passing pada Sekolah Sepak Bola (SSB) Putra Mojosongo Club Tahun

\begin{abstract}
ABSTRAK
Tujuan dari penelitian ini adalah : (1) Mengetahui pengaruh latihan passing menggunakan target terhadap kemampuan passing dalam permainan sepak bola. (2) Mengetahui pengaruh latihan passing berpasangan terhadap kemampuan passing dalam permainan sepak bola. (3) Mengetahui perbedaan pengaruh antara passing menggunakan target dan latihan passing berpasangan terhadap kemampuan passing. Metode penelitian yang digunakan adalah metode eksperimen. Subjek dalam penelitian ini adalah atlet SSB Putra Mojosongo Club yang berjumlah 20 atlet. Metode pengumpulan data yang digunakan adalah dengan menggunakan tes akurasi passing yang dinamakan tes short passing dari jarak 10 meter ke arah sasaran gawang yang memiliki lebar 1 meter, yang difungsikan sebagai alat untuk mendapatkan data. Berdasarkan hasil analisis data : (1) Terdapat pengaruh yang signifikan antara latihan passing menggunakan target terhadap akurasi passing pada altet SSB Putra Mojosongo Club. Pernyataan ini diperkuat dengan hasil uji $\mathrm{t}$ berpasangan dengan nilai $p$-value $<0,05$ ( $p$-value $=0,000)$. (2) Terdapat pengaruh yang signifikan antara latihan passing berpasangan terhadap akurasi passing pada atlet SSB Putra Mojosongo Club. Hal ini ditunjukkan berdasarkan hasil uji $\mathrm{t}$ berpasangan dengan nilai $p$-value $<0,05$ ( $p$-value $=0,008)$. (3) Terdapat perbedaan pengaruh antara latihan passing menggunakan target dan latihan passing berpasangan terhadap akurasi passing pada altet SSB Putra Mojosongo. Hal ini diketahui melalui hasil uji t tidak berpasangan dengan nilai $p$-value $<0,05$ ( $p$-value $=0,011)$. Pada persentase peningkatan kemampuan masing-masing kelompok diketahui pada kelompok latihan passing menggunakan target memiliki peningkatan sebesar 63,64\% sedangkan pada kelompok latihan passing berpasangan hanya mengalami peningkatan sebesar $25,64 \%$.

\section{ABSTRACT}

The objectives of this study are: (1) To determine the effect of training through the use of targets on soccer ability. (2) Knowing the effect of pair training on abilities through soccer games. (3) Knowing the difference in effect between using targets and pair training on passing abilities. The research method used is the experimental method. The subjects of this study were athletes of the SSB Putra Mojosongo Club which can accommodate 20 athletes. The data test
\end{abstract}


method used is to use a passing accuracy test called a short passing test from a distance of 10 meters towards the target goal which has a width of 1 meter, which functions as a means of obtaining data. Based on the results of data analysis: (1) there is a significant effect between passing training using targets on the passing accuracy of the SSB Putra Mojosongo Club altet. This statement states with paired t-test results with a p-value $<0.05$ (p-value $=0.000$ ). (2) there is a significant effect between the under-passing practice on the passing accuracy of the SSB Putra Mojosongo Club athletes. This is shown based on the results of the paired t test with a p-value <0.05 ( $p$-value $=0.008$ ). (3) the existence of an effect between target training and paired training on passing accuracy at SSB Putra Mojosongo altet. This is known through the unpaired test results with a p-value $<0.05$ ( $p$-value $=0.011)$. In the percentage increase in the ability of each group, it is known that the passing training group using the target has an increase of $63.64 \%$ while the paired passing training group only experienced an increase of $25.64 \%$.

\section{Pendahuluan}

Sepak bola merupakan sebuah permainan yang dimaiankan beregu, yang masing-masing regu terdiri dari penjaga gawang, pemain belakang, pemain tengah, dan pemain depan. Seorang penjaga gawang boleh menggunakan semua anggota tubuh untuk bermain kecuali tangan (hanya untuk di daerah gawangnya). Menurut Darmawan (2020) bahwa sepak bola merupakan olahraga permainan yang dimainkan oleh dua tim, massing-massing tim bertujuan menciptakan gol ke gawang lawan sebanyak-banyaknya dan berusaha menjaga gawang timnya agar tidak kemasukan bola. Untuk regu yang dapat mencetak gol paling banyak ke gawang lawan dalam waktu 2 x 45 (90 menit) maka regu tersebutlah yang menang. Sepak bola adalah olahraga yang sangat digemari di seluruh dunia. Semua kalangan dan golongan suka bermain sepak bola, mulai dari anak-anak, remaja, dewasa dan orang tua di belahan dunia gemar bermain sepak bola.

Permainan sepak bola dibutuhkan komunikasi antar pemain untuk menjalin kerjasama yang baik dalam bermain sebagai kunci kesuksesan. Pemain sepak bola juga harus menguasai teknik dasar dalam bermain sepak bola, menurut Herwin (2004: 21-24) gerak atau teknik dasar permainan sepak bola meliputi gerak atau teknik tanpa bola dan gerak atau teknik dengan bola. Gerak atau teknik tanpa bola merupakan gerak tanpa menggunakan bola yang dilakukan dalam permainan sepak 
bola separti berjalan, berjingkat, melompat, meloncat, berguling, berputar, berbelok, berkelit, dan berhenti tiba-tiba, sedangkan gerak atau teknik dengan bola merupakan gerak atau teknik dalam permainan sepak bola dengan menguasai bola yang meliputi kemampuan pengenalan bola dengan bagian tubuh (ball feeling), menendang bola (passing), menendang bola ke gawang (shooting), menggiring bola (dribling), menerima dan menguasai bola (receiveing and controlling the ball), menyundul bola (heading), gerak tipu (feinting), merebut bola (sliding tackle), melempar bola kedalam (throw-in) dan menjaga gawang (goal keeping).

Salah satu syarat untuk dapat bermain sepak bola dengan baik adalah pemain harus dibekali dengan kemampuan dasar yang baik karena pemain yang memiliki kemampuan dasar yang baik, pemain tersebut cenderung dapat bermain sepak bola dengan baik pula. Kemampuan dasar dalam permainan sepak bola ada beberapa macam, seperti shooting (menendang bola ke arah gawang), passing (mengoper), heading (menyundul bola), dan dribbling (menggiring bola). Dari berbagai faktor penghambat munculnya pemain-pemain sepak bola yang berbakat tersebut salah satunya karena kurangnya pengetahuan pemain tentang teknik dasar yang benar dalam permainan sepak bola apalagi dijenjang-jenjang lembaga pendidikan formal. Di dalam lapangan berbagai kombinasi teknik dan gerakan yang dimiliki setiap pemain sangatlah mendukung dalam penguasaan bola untuk mencapai sebuah kemenangan. Namun kurangnya latihan akan menjadi masalah besar bagi pemain jika ingin meningkatkan kemampuan.

Teknik yang dikuasai juga hanya menendang dan mengoper, sementara untuk menjadi pemain sepak bola yang handal pemain diharuskan mampu untuk mengoper dan mengontrol bola. Sepak bola juga memiliki berbagai peraturan yang harus dipatuhi, antara lain adalah pemain tidak boleh mencederai dengan sengaja pemain lawan, apabila terjadi maka wasit akan mengeluarkan kartu kuning sebagai peringatan atau bahkan kartu merah langsung yang artinya pemain tersebut harus ke luar lapangan permainan. 
Pembinaan olahraga prestasi sepak bola membutuhkan waktu yang panjang, terprogram dan dimulai dari usia dini. Untuk melakukan suatu pembinaan diperlukan suatu wadah atau organisasi yang dapat membina pemain sehingga menjadi pemain yang handal. Selain itu adanya sarana prasarana atau fasilitas yang mendukung terlaksananya latihan yang sistematis dan kontinyu, dan hal yang paling penting lainnya adalah pendanaan merupakan faktor pokok untuk terlaksananya tujuan suatu organisasi. Persatuan Sepak Bola Seluruh Indonesia (PSSI) sebagai induk organisasi sepak bola dalam memajukan prestasi selalu berusaha memajukan sepak bola dengan cara mengadakan kompetisi-kompetisi atau pertandingan di tingkat junior di bawah usia 23 tahun atau senior di atas usia 23 tahun dan diadakannya bibit pemain berprestasi baik melalui organisasi atau perkumpulan sepak bola di daerah. Dewasa ini banyak SSB yang didirikan. Berjalan ke depan SSB seperti ini mulai membuat rencana jauh ke depan. Mereka mulai mengembangkan ke sebuah prestasi ataupun regenerasi bibit masa depan. Dengan demikian tujuan SSB menjadi jauh berkembang, mulai dari sarana berkumpul menjadi sebuah tempat untuk mengembangkan bakat anak didik supaya menjadi pemain sepak bola yang profesional. Faktor penting yang lain yang dapat mempengaruhi prestasi pemain sepak bola adalah penguasaan teknik dasar sepak bola oleh para pemain.

Permainan sepak bola didominasi oleh penguasaan bola passing cepat antar pemain. Permainan yang cepat biasanya didukung oleh kualitas passing yang baik karena dibutuhkan untuk membuat irama permainan dan penguasaan bola di lapangan. Salah satu kelemahan yang mendasar dari permainan yang bisa mempengaruhi performa team saat pertandingan adalah kualitas passing. Begitu juga dengan perkembangan kondisi pemain di SSB Putra Mojosongo Club Tahun 2020 yang sangat kurang sekali. Melihat dari beberapa pertandingan yang dilakukan SSB Putra Mojosongo Club Tahun 2020 selalu menelan hasil yang kurang memuaskan, salah satu faktornya dikarenakan kualitas passing antar pemain dalam pertandingan kurang maksimal. Berdasarkan pengamatan yang dilakukan dalam latihan SSB Putra 
Mojosongo Club untuk dijadikan objek penelitian, dapat dilihat karena masih banyak anak atau atlet yang belum mampu melakukan passing secara tepat, hal ini ditunjukkan pada saat bermain banyak atlet yang melakukan kesalahan dalam passing, antara lain: passing tidak sampai kepada teman, passing yang terlalu kencang sehingga teman sulit untuk menguasai bola, passing yang asal-asalan sehingga tidak jelas ke mana bola akan diberikan, passing yang tidak tepat ke arah teman sehingga salah memberi umpan.

Oleh karena itu, seorang pemain sepak bola yang tidak menguasai teknik dasar sepak bola tidak akan menjadi pemain yang baik. Teknik dasar bermain sepak bola menentukan sampai di mana pemain dapat meningkatkan kualitas permainan. Hasil observasi di lapangan peneliti mengamati salah satu SSB yang berada di Surakarta yaitu SSB Putra Mojosongo Club yang bertempat latihan di Mojosongo Surakarta. SSB ini di bawah asuhan Bapak Anto. Dilihat dari seluruh jumlah pemain yang berada di SSB Putra Mojosongo Club yaitu berjumlah 65 pemain.

Hasil pengamatan observasi di lapangan pemain SSB Putra Mojosongo Club belum mampu menguasai teknik dasar passing dengan akurasi yang benar. Minimnya variasi latihan dapat menjadikan pemain kurang mampu menguasai teknik dasar passing. Dalam permainan sepak bola salah satu teknik dasar yang paling dominan digunakan adalah passing. Passing dalam permainan sepak bola memiliki tujuan yaitu mengoper bola pada teman satu tim agar dapat menciptakan ruang, sehingga pemain dapat menciptakan gol ke gawang lawan dan dapat mempertahankan daerah pertahanan bagi pemain bertahan. Dalam melakukan passing hal yang perlu diperhatikan yaitu ketepatan hasil passing. Agar mengahasilkan passing yang akurat seorang pemain harus fokus terhadap salah satu titik pusat sasaran dan apabila titik pusat sasaran semakin diperkuat maka tinggat konsentrasi yang dibutuhkan semakin besar dan hasil akurasi pun akan semakin tinggi.

Alasan peneliti melakukan penelitian di SSB Putra Mojosongo Club karena peneliti melihat adanya masalah para atlet SSB Putra Mojosongo Club dalam 
melakukan passing. Melihat banyaknya peminat dan semangatnya para atlet SSB Putra Mojosongo Club saat berlatih dan bertanding. Oleh karena itu, untuk ke depannya SSB Putra Mojosongo Club harus memperbaiki kualitas sarana prasarana dan juga variasi latihan akurasi passing. Kesalahan dalam melakukan passing dikarenakan masih banyak anak yang belum mengetahui teknik passing yang benar dan juga variasi latihan passing yang harus diperbanyak lagi. Bersumber dari pendapat di atas mengenai pentingnya akurasi passing bagi pemain sepak bola, untuk itu di samping sarana dan prasarana bersama-sama dengan pelatih perlu memilih metode latihan mana yang akan digunakan dalam meningkatkan akurasi passing atlet SSB Putra Mojosongo Club.

Berdasarkan latar belakang masalah maka dapat dirumuskan masalah sebagai berikut:

1. Apakah ada pengaruh latihan passing menggunakan target terhadap kemampuan passing dalam permainan sepak bola?

2. Apakah ada pengaruh latihan passing berpasangan terhadap kemampuan passing dalam permainan sepak bola?

3. Apakah ada perbedaan pengaruh antara latihan passing menggunakan target dan latihan passing berpasangan terhadap kemampuan passing dalam permainan sepak bola?

\section{Metode}

Penelitian yang penulis buat merupakan eksperimen menurut Sandjaja (2006: 123) merupakan penelitian yang dengan sengaja membangkitkan suatu kejadian atau keadaan, kemudian diteliti bagaimana akibatnya. Dalam penelitian ini akan dilakukan tes awal pada sampel untuk mengetahui kemampuan awal dari sampel penelitian. Kemudian sampel akan dibagi kedalam dua kelompok penelitian dengan menggunakan metode Ordinal.

Populasi pada penelitian ini adalah atlet Sekolah Sepak Bola (SSB) Putra Mojosongo Club Surakarta yang berjumlah 65 orang. Sedangkan untuk sampel 
ditarik kesimpulan yang berjumlah 20 orang. Penelitian ini dilakukan selama enam minggu, dalam satu minggu dilakukan latihan selama tiga kali pertemuan.

Menurut Toto Subroto (2007:12.14) Untuk memperoleh data yang diperlukan dalam penelitian ini dilakukan dengan menggunakan tes akurasi passing yang dinamakan tes short passing dari jarak 10 meter ke arah sasaran gawang yang memiliki lebar 1 meter, yang difungsikan sebagai alat untuk mendapatkan data.

\section{Hasil dan Pembahasan}

\section{a. Hasil}

Data hasil penelitian sebagai berikut:

Tabel 2.1 Hasil Uji Deskriptif Data

\begin{tabular}{|l|c|c|c|c|}
\hline \multirow{2}{*}{} & \multicolumn{2}{|c|}{ Latihan Menggunakan Target } & \multicolumn{2}{c|}{ Latihan Berpasangan } \\
\cline { 2 - 5 } & Pretest & Post-test & Pretest & Post-test \\
\hline Mean & 4,4 & 7,2 & 3,9 & 4,9 \\
\hline Median & 4,5 & 7 & 4 & 5 \\
\hline Standar deviasi & 1,776 & 1,751 & 1,37 & 1,853 \\
\hline Varians & 3,156 & 3,067 & 1,878 & 3,433 \\
\hline Minimum & 2 & 5 & 2 & 2 \\
\hline Maksimum & 8 & 10 & 6 & 7 \\
\hline Range & 6 & 5 & 4 & 5 \\
\hline
\end{tabular}

Pada tabel diatas tampak hasil uji deskriptif data pada kelompok pretest dan post-test pada masing masing kelompok data menunjukkan nilai yang beragam. Pada kelompok latihan passing menggunakan target didapatkan hasil pretest dengan nilai mean dan median secara berurutan yaitu 4,4 dan 4,5. Kelompok ini memiliki nilai standar deviasi 1,776 dengan varians sebesar 3,156. Kelompok ini juga memiliki nilai range 6 dengan nilai minimum berada pada 2 dan nilai maksimum pada 8. Pada pengujian post-test perubahan tampak pada seluruh komponen uji deskriptif data. Nilai mean mengalami perubahan menjadi 7,2 dengan median sebesar 7. Standar deviasi dan varians juga mengalami perubahan menjadi 1,751 dan 3,067. Nilai minimum dan maksimum kelompok ini mengalami perubahan menjadi 5 dan 10 dengan range sebesar 5 .

Hasil uji latihan passing berpasangan juga menunjukkan hasil yang serupa. Pada hasil pretest kelompok ini didapatkan mean dengan nilai 3,9 dan median 
dengan nilai 4. Kelompok ini memiliki standar deviasi sebsesar 1,37 dengan varians bernilai 1,878. Hasil nilai pretest pada kelompok ini memiliki nilai minimum 2 dan nilai maksimum 6 serta nilai range 4 . Setelah perlakuan diberikan dan dilakukan post-test tampak bahwa kelompok ini juga mengalami perubahan nilai pada komponene hasil uji deskriptifnya. Nilai mean pada kelompok ini berubah menjadi 4,9 dan nilai median berubah menjadi 5. Hasil uji juga menunjukkan perubahan pada standar deviasi dan varians yang secara berurutan bernilai 1,853 dan 3,433. Nilai minimum kelompok ini tetap sama dengan nilai 2 dengan perubahan nilai maksimum menjadi 7 dan nilai range sebesar 5 .

Tabel 2.2 Rangkuman Hasil Uji Perbedaan Tes Akhir antara Kelompok Latihan Passing Menggunakan Target dan Latihan Passing Berpasangan

\begin{tabular}{|l|l|l|l|l|}
\hline & N & $\begin{array}{c}\text { Mean } \pm \text { std. } \\
\text { dev. }\end{array}$ & $\begin{array}{c}\text { Perbedaan } \\
\text { Rerata (IK95\%) }\end{array}$ & $\boldsymbol{p}$-value \\
\hline $\begin{array}{l}\text { Latihan } \\
\text { Mengunakan Target }\end{array}$ & 10 & $7,2 \pm 1,751$ & $2,3 \pm 0,806$ & 0,011 \\
\hline $\begin{array}{l}\text { Latihan } \\
\text { Berpasangan }\end{array}$ & 10 & $4,9 \pm 1,853$ & & \\
\hline
\end{tabular}

Tabel diatas menunjukkan hasil uji $t$ tidak berpasangan yang dilakukan antara nila post-test pada kedua kelompok latihan. Pada tabel terlihat bahwa hasil uji $\mathrm{t}$ tidak berpasangan antara dua kelompok tersebut menghasilkan nilai $p$-value $=0,011$. Pernyataan ini mengindikasikan diterimanya hipotesis yang telah disusun. Sehingga dapat diinterpretasikan bahwa terdapat perbedaan pengaruh yang signifikan antara latihan passing menggunakan target dengan latihan passing berpasangan terhadap akurasi passing sepak bola.

\section{b. Pembahasan}

\section{Pengaruh Latihan Passing Menggunakan Target Terhadap Akurasi Passing}

Hasil penelitian yang telah dipaparkan di atas menyebutkan bahwa terdapat pengaruh yang signifiakn antara metode latihan passing menggunakan 
target terhadap akurasi passing dalam permainan sepakbola. Penyataan tersebut didukung dengan hasil uji $\mathrm{t}$ berpaasangan yang telah didapat dengan $p$-value = 0,000. Pernyataan tersebut selaras dengan penelitian Mubarok (2019) yang menyebutkan bahwa penggunaan metode latihan passing menggunakan sasaran berurutan memiliki pengaruh yang signifikan terhadap akurasi passing permainan sepakbola pada anggota Unit Kegiatan Mahasiswa Universitas Siliwangi Tasikmalaya yang dibuktikan dengan hasil uji $\mathrm{t}$ dengan nilai thitung $=$ 484,62 (thitung $>$ ttabel; $_{\text {tabel }}=1,6$ ). Penggunaan target berupa lingkaran hula hop sebagai media akan membantu para atlet agar dapat memfokuskan arah passing sesuai dengan sasaran. Selain itu, dengan repetisi passing secara terus menerus akan membentuk koordinasi antara mata, kaki dan teknik passing sehingga passing yang dilakukan dapat masuk ke dalam target. Passing yang semakin terarah dan sesuai dengan target menunjukkan bahwa akurasi passing semakin meningkat.

\section{Pengaruh Latihan Passing Berpasangan Terhadap Akurasi Passing}

Melalui pembahasan diatas diketahui bahwa terdapat pengaruh yang signifikan antara metode latihan passing berpasangan terhadap akurasi passing sepakbola. Hal ini ditandai dengan hasil uji t berpasangan dengan nilai $p$-value = 0,008. Oktavia (2017) dalam penelitiannya juga menyebutkan bahwa terdapat pengaruh signifikan antara latihan berpasangan terhadap ketepatan passing pada peserta ekstrakulikuler futsal putri SMP Negeri 21 Malang yang dibuktikan dengan hasil thitung $=9,33\left(t_{\text {hitung }}>t_{\text {tabel }}\right.$; tabel $\left.=2,782\right)$. Melalui latihan passing secara berpasangan para atlet binaan dihadapkan secara langsung dengan simulasi passing secara nyata. Hal ini menjadikan para atlet lebih terbiasa ketika melakukan passing dalam pertandingan.

3. Perbedaan Pengaruh Antara Latihan Passing Menggunakan Target Terhadap Akurasi Passing

Seperti yang telah dipaparkan dalam hasil penelitian di atas, kedua metode latihan diketahui memiliki pegaruh yang signifikan terhadap akurasi passing sepakbola. Akan tetapi berdasarkan hasil penelitian di atas, diketahui 
bahwa hasil uji t tidak berpasangan menunjukkan hasil $p$-value $=0,011$ yang menunjukkan bahwa terdapat perbedaan yang signifikan antara latihan passing menggunakan target dengan latihan passing secara berpasangan. Berdasarkan persentase peningkatan akurasi passing diketahui bahwa kelompok latihan passing menggunakan target memiliki persentase peningkatan akurasi passing sebesar 63,64. Nilai ini lebih besar dari pada persentase peningkatan akurasi kelompok latihan passing berpasangan yang hanya sebesar 25,64\%.

Berdasarkan pengamatan yang telah dilakukan diketahui bahwa pada metode latihan passing menggunakan target para altet dituntut untuk dapat melakukan passing dengan lebih terkontrol, fokus dan terarah agar dapat masuk melalui target yang disediakan. Sedangkan pada latihan passing secara berpasangan para atlet hanya berfokus pada memperbaiki teknik passing tanpa adanya fokus terhadap titik tertentu karena pasangan latihan juga dapat bergerak mengikuti arak gerak bola. Sehingga hal ini mengakibatkan akurasi pada latihan passing secara berpasangan kurang terbentuk dengan baik.

\section{Simpulan}

Berdasarkan hasil penelitian dan analisis data yang telah dilakukan, dapat diambil kesimpulan sebagai berikut :

1. Terdapat pengaruh yang signifikan antara latihan passing menggunakan target terhadap akurasi passing pada altet SSB Putra Mojosongo Club. Pernyataan ini diperkuat dengan hasil uji t berpasangan dengan nilai $p$-value $<0,05$ ( $p$-value $=$ $0,000)$.

2. Terdapat pengaruh yang signifikan antara latihan passing berpasangan terhadap akurasi passing pada atlet SSB Putra Mojosongo Club. Hal ini ditunjukkan berdasarkan hasil uji t berpasangan dengan nilai $p$-value $<0,05$ ( $p$-value $=0,008$ ).

3. Terdapat perbedaan pengaruh antara latihan passing menggunakan target dan latihan passing berpasangan terhadap akurasi passing pada altet SSB Putra Mojosongo. Hal ini diketahui melalui hasil uji t tidak berpasangan dengan nilai $p$-value $<0,05$ ( $p$-value $=0,011)$. 


\section{Referensi}

Sandjaja. 2006. Panduan Penelitian. Jakarta: Prestasi Pustaka Raya

Subroto, Toto. 2007. Permainan Besar. Universitas Terbuka. Jakarta.

Herwin. 2004. Keterampilan Sepakbola Dasar. Diktat. FIK UNY, Yogyakarta.

Muta'al, T. A. \& Komaini, A. 2019. “Pengaruh Latihan Passing Dengan Variasi Target Terhadap Kemampuan Passing Pada Tim Sepakbola SMAN 3 Bungo". Jurnal STAMINA, 2 (6): 12-20.

Darmawan. 2020. Perbedaan Pengaruh Metode Latihan dan Koordinasi Mata-Kaki Terhadap Kemampuan Menggiring Bola dalam Permainan Sepak Bola. Universitas Tunas Pembangunan Surakarta. 